\title{
Understanding the Drivers of Partnership Success
}

\author{
Rehema Batti \\ IMD Business School, Lausanne, Switzerland
}

Email address:

rehemabatti2012@gmail.com

\section{To cite this article:}

Rehema Batti. Understanding the Drivers of Partnership Success. Humanities and Social Sciences Vol. 7, No. 1, 2019 , pp. $21-27$. doi: $10.11648 /$ j.hss.20190701.13

Received: March 2, 2018; Accepted: April 4, 2018; Published: March 25, 2019

\begin{abstract}
Partnerships are effective and sustainable mechanisms that enable development NGOs effectively achieve their mandates and project interventions at community level. However many partnerships fail to achieve their envisioned outcomes due to factors that limit or hinder their success. It is often difficult to consistently manage partnership success when the partnership involves organizations with different mandates, organizational structures, values, professional capacities and limited resources. The purpose of the study was to explore factors that are perceived as key in facilitating partnership success from the perspective of local NGOs engaged in development partnerships. Experiences and understanding of NGO leaders and staff engaged in partnership work were explored through a series of interviews. The study revealed the following factors that were perceived to be key to nurturing successful partnerships; commitment, communication, shared vision and purpose, collaborative leadership and realistic funding. It is important for any agency or institution seeking to collaborate with others to identify and monitor both the' hard' and 'soft' aspects that promote partnership success.
\end{abstract}

Keywords: Partnership Success, Collaboration, Alliances and NGOs

\section{Introduction}

Partnerships play a key role in sustainable development [1]. They provide an opportunity to facilitate scale up of development interventions and leveraging of services, expertise and sustainable resources at community level.

There is increased interest in engaging in partnerships because more resources can be accessed to address local needs [2] through such collaborations.

\section{Partnership Concept and Value}

The term 'partnership' is widely used in the development field and it's sometimes substituted with words such as 'collaborations' or 'alliances'.

Legitimate relationships between organizations are diverse and include collaboration, cooperation, alliances, consortia, networks or joint ventures however; not all of those can be called partnerships [3].

Partnerships are defined as collaborative relationships between various parties, who aim to achieve a common purpose, and to share risks, responsibilities, resources and benefits [4].

Partnership is about working together to accomplish agreed results and accepting joint responsibility for achieving them [5]. These definitions emphasize the aspects a shared vision, shared resources and joint responsibility to undertake a specified purpose to achieve defined results.

Successful partnerships provide diverse benefits to the participating organizations. Partnerships can bring about both intangible and tangible value when they are well developed, managed and governed.

There are four different types of value gained from involvement in partnership [6];

i. Associational value which refers to benefits that accrue to partners by having a partnership;

ii. Transferred resource value which is experienced as a result of resource transfers between partners;

iii. Interaction value in partnership relates to aspects such as shared knowledge and improved trust between partners;

iv. Synergistic value is generated through knowledge, skills or resource complementarity that would otherwise not have occurred at individual organizational level.

For example, partnerships in the research field were viewed as door openers whose comparative advantages were;

i. Increased visibility and attractiveness

ii. Increasing their influence and improving their access to new resources.

iii. Better access to information and new fields of research.

iv. Enhanced radius of contacts and interaction, reducing scientific isolation, facilitating access to international 
scientific outreach.

v. Easier access to communities and policymakers.

vi. Better opportunities to give voice to delicate issue [7].

The extent to which types of value is experienced is determined by the interests of organizations, level of integration and interaction between the various partners, and nature of resources transferred [8].

Unfortunately due to the challenges and limitations experienced in partnership many organizations do not consistently experience the value and benefits of these engagements.

\section{Partnership Working}

The growing emphasis on collaboration between agencies and sectors is creating the need for organizations to develop their capacity for working with other stakeholders. The combination of strengths of the different organizations when well-coordinated results in greater success.

However, failure rate among alliances is often reported to exceed $60 \%$ [9].For many partnerships absence of robust governance and relational management systems seem to contribute to this failure. As a result, the leaders of even the best performing partnerships find it increasingly difficult to deliver on their ambitious goals [10].

Most partnerships lack formal governance structures and this undermines accountability and meaningful cooperation. Without governance structures partnerships become informal networks with high reputational and financial risks.

Organizational factors like size, culture and values, resources, project implementation systems, strategy and the policies can impact the effectiveness of partnership governance mechanisms.

Synergy is considered a key indicator of successful partnership. Partnerships are expected to create synergy to enable them reach their full potential in solving complex problems, however different scholars observe that most partnerships are far from realizing this potential, [11, 12].

Factors that affect the capacity of partnerships to achieve synergy include;

i. Type and number of stakeholders involved;

ii. Level and type of partner capacity;

iii. Leadership involvement;

iv. Resources available;

v. Scope and duration of partnership engagement;

vi. Infrastructure;

vii. The external operating environment.

Without synergy the potential of partnership engagements to achieve sustainable outcomes is minimized. When there is no synergy or any significant value to be gained from pooling competencies, skills and resources internally or externally then this kind of engagement ceases to qualify as a partnership [1].

While the choice to work in partnerships is more or less chosen by the organizations' independently, unfortunately others choose to work in partnerships because they are coaxed along by the prospect of funding or other incentives or threat of de-funding and other disincentives [13].

In practice, NGOs often encounter diverse internal and external changes that impact their involvement in partnerships. Turf battles, inadequate capacity, lack of trust, and competition for funding make organizations unwilling to fully commit to potentially productive partnerships unless mutual accountability is assured through some type of explicit and coherent structure [14].

Inclusive and balanced participation promotes a spirit of trust and each partner gradually develops an interest in the success of the partnership.

Effective participation has been noted to promote partnership effectiveness [15]. Organization and individuals' input and involvement can improve programs interventions developed, ensure services are delivered in a more effective manner and help monitor the partner representation.

The more a specific stakeholder group is affected by a component of the project, it is crucial for them to be informed and encouraged to participate [16]. However, the degree and level of participation is affected by characteristics of the partnership such as duration, scope, nature of partnership structure, the type of interventions and governance mechanisms.

Diverse perspectives and misleading assumptions held on what partnerships entail by those who fund, initiate, engage or facilitate partnerships continue to undermine many partnership efforts initiated at community level.

\section{Justification and Objective of the Study}

Well-planned partnerships are one of the best mechanisms for improving the quality and co-ordination of services, particularly to vulnerable individuals whose needs might otherwise be neglected [17].

Local community based partnerships have shown success in addressing development issues, therefore it has become critical for them to perform well [18]. Therefore the need to understand what underlies partnership success, and identify ways NGOs can better collaborate to ensure their success.

Many international NGOs and local NGOs are adopting a partnership approach as a development model to facilitate service delivery within selected regions and communities. Yet many fail to understand the factors that will ensure their success and sustained performance.

Partnerships with not-for profit entities or non-governmental organizations are unique. These types of partnerships are becoming common yet current academic research has very little to say about how to successfully manage these types of alliances [17].

This study sought to identify aspects that are perceived to nurture and sustain partnership success. The study focused on getting the views from local NGOs to address a gap, observed that existing literature does not capture views from Southern NGOs about partnerships working [5] and that Southern NGOs continue to be frustrated by the relational dynamics in these partnerships.

Organizations often engage in partnerships to increase their competitiveness, viability and upscale their interventions. Partnerships are powerful vehicles when managed well and there is need to understand their potential as well as their risks 
[13].

If partnerships are to continue being viable and credible vehicles of development then they need to demonstrate they can facilitate the necessary change required at community level.

The antecedents of partnership formation and the characteristics of the resulting cooperative working relationship have been widely explored in the literature. However, a clear understanding of characteristics associated with partnership success is lacking [19].Hence the need for exploring and understanding factors that drive success in partnerships to minimize the risks.

This study sought to fill the knowledge gaps highlighted by different authors through identifying factors that are perceived to contribute to successful partnerships between local and international NGOs.

The study targeted NGOs involved in collaborations with INGOs in the development sector and used a case study approach.

\section{Study Findings and Observations}

The respondents from local NGOs were requested to highlight five key factors that they perceived to contribute to cultivating a successful partnership.

The evidence from the study highlighted the following aspects; Commitment (76\%); Communication (68\%); Shared vision and purpose $(60 \%)$; Collaborative leadership (48\%) and Realistic funding (48\%). The scores were based on the frequency of respondent ratings for each factor.

The study findings were consistent with the other studies on factors that facilitate partnership success [20, 21]. The following highlights the factors perceived to determine success in partnerships between NGOs.

\subsection{Commitment}

Commitment to an alliance signals a belief that the partnership creates value and that engaging in the partnership will bring lasting results. Effective partnerships have the right decision makers at the table with a commitment to contribute time and resources [22].Consistent commitment from each organization or individual is key to partnership success.

Partner commitment was identified as a trait that had positive influence on partnership performance [23]. Inadequate commitment among NGOs in partnership is however a recurring challenge. Sustained commitment is a must and it is important for NGOs to understand why they are collaborating or partnership success becomes elusive.

Partnerships are little more than dialogues until those involved have made a tangible commitment to collaborate. It is important that everyone understands and agrees to the purpose of the collaboration, the degree of commitment required, and the expectations of partners involved in the effort [24].

Commitment is reflected in the terms of the degree or level of engagement, contribution of resources, accountability and focus to achieve partnership goals, learning, facilitative operational processes and adaptability to changes in the partnership environment.
Partnerships require solid commitment to shared goals, shared responsibility, mutual authority and accountability for success, and sharing of resources, risks, and rewards.

Commitment of organizations is affected by the benefits experienced and whether the mandate of the organization is being met through the engagement. An organization's capacity, experience in collaboration and individual's attitude will also affects its commitment.

It has been observed that committed partners are likely to be more cooperative, communicative, flexible and demonstrate persistent willingness to make future relation- specific investments [25].

Therefore partnerships need mechanisms that ensure each partner is responsive and responsible for delivering their commitments as planned.It is important for partnerships to develop structures and processes that facilitate and sustain the partner's commitments. Strategic recruitment of organizations and allocation of specific responsibilities helps manage commitment levels.

Attitudinal commitment is what drives partners to strive to nurture and foster behaviours that ensure relations grow beyond the contractual framework [26].Commitment can be strengthened through collaborative agreements and partnership principles. This enables mutual accountability and promotes commitment.

\subsection{Communication}

Open and frequent communication was cited as key in ensuring success in partnership. Good communication is crucial to the success of any partnership, but its importance is often underestimated.

Open and frequent communications assists in retaining partner organization interest through increasing their understanding, and commitment. The quality, timeliness and the structure of communication are aspects that facilitate the partnership's effectiveness and efficiency.

Communication has been identified as the lubricant that keeps the engine of partnership running [27]. Many partnerships face inter organizational conflicts during their operation because of the diverse missions and organizational cultural orientation of the partners. Those involved in partnerships have a role to uphold open and sincere communication with the rest of the team if they are to work effectively together.

Communication channels in partnerships have tended to focus more on aspects of project delivery, especially between those delivering the services, as opposed to a wider, more inclusive dialogue-based communication at a strategic level [28].

A partnership should create continuous and convenient opportunities for feedback to support timely decision making and resolution of conflicting issues or risks. Effective communication practices support the achievement of partnership's goals and objectives.

Effective communication is crucial in resolving disagreements; speeding decision-making and achieving shared understanding of partnership goals [25].Open and frequent communication helps to advance partnership objectives, and increase its impact. 
Development of a communication strategy is an important tool that helps in developing effective communication channels that focus on the expectations and needs of each partner.

\subsection{Shared Vision and Purpose}

It is important for the partnership to understand that each partner has their own motivation in joining the partnership and the driving force needs to be understood early enough to enhance better management of partner expectations.

Vision and purpose guide a partnership [29]. This finding is also supported by other studies that noted that a shared understanding of a partnership's purpose and direction, and how each partner can best contribute, is important in developing and maintaining a stable partnership [30].

Many partnerships however do not have a clear vision or mission that guides the partnership work. Every partner within a partnership should know precisely why they are there, what they bring to the alliance, what to expect from others, and of course what is to be achieved together or in other words, what is expected of them. Unfortunately, many partnerships lack clarification as to the roles and functions of the various organizations [31] that align to the vision and purpose.

Partnerships that succeed are those that have a vision and purpose that is shared among all the participating organization and they commit to achieving that endeavor through collaborative efforts.

A shared vision or purpose clearly defined at the beginning is the engine that drives partnership success; while each NGO should have its own distinct mission; a shared vision will help like-minded groups set common goals and deliver a common message for change [32].

Partnership objectives should ideally align to those of the partner organizations' mandate. Partnerships have to be strategic in refining objectives to address both its mandate and the mandates of the participating organizations.

A shared understanding of a partnership's purpose and direction, and how each partner can best contribute, is necessary to build and maintain a strong partnership. In addition, as direction and vision evolve, partnerships must respond to changing environments [33].

Organizations need to understand and leverage the added value expected from the partnership's work. It is important for participating organizations' to ensure their alignment with the partnership vision and objectives as the partnership progresses.

A partnership chances of success increase when all the participating organizations and individuals have an equally strong interest in the partnership's success.

\subsection{Collaborative Leadership}

The presence of collaborative leadership fosters shared purpose, ownership, commitment and stimulates team cohesion among participating entities. How organizations exhibit and demonstrate leadership qualities can often lead to success or failure in the partnership [34].

Leadership in partnership engagements requires different competencies and approaches. Unfortunately, the assumption that the leadership skills used in an individual NGO set up can be used in a partnership setting creates challenges in many partnerships.

Many leaders who are considered effective within their organizations lack the leadership competencies required to develop and nurture a partnership engagement. Often these individuals utilize or over-rely on traditional leadership styles to manage such engagements.

Partnerships imply a shared leadership among respected individuals who are empowered by their own organizations and trusted by partners to build consensus and resolve conflicts [21].Different individuals or organizations contribute different types of leadership within the partnership setting. These skills and experiences need to be identified and harnessed.

The attendance or nonattendance of senior staff to forums was cited as an indicator of the strength or absence of leadership endorsement for a partnership activity and this view was also observed by Boydell [35]. Therefore, a senior leadership presence or sponsorship enhances commitment and empowers staff to enter into partnerships with a sense of confidence and an assurance of organizational support.

Partnerships require organizational leaders to embrace values and practice behaviours that promote a conducive environment for partnership growth. Leadership credibility and developing appropriate competencies are key in sustaining partnership momentum at both organizational and partnership level.

Leaders with collaborative skills are crucial as they build on the partnership's viability, promote accountability and facilitate effective participation among the participating organizations.

\subsection{Realistic Funding}

The underlying motivation for any partnership is the funding and implementation of the projects. Many partnerships struggle with issues of erratic funding, delays or under-funding that affect projects and sustenance of partnership activities. Sometimes the funding practices and priorities do not necessarily align to the mission of the participating organization, or address the felt needs of the communities or support sustainable emerging practices.

Partnerships effectiveness is hampered by diverse obstacles related to funding. For instance there is always a risk that the funding aspect will result into a funder - client relationship that distorts the relations [36].

Engaging in more strategic partnership requires that commitments and priorities focus on providing resources that are adequate, realistic and responsive based on the context, capacity of the organization, area of operation and perceived needs of the targeted communities.

Having the required resources tied to the priorities identified is key but equally important is the when, the how, the how much and what of the funding aspects. Time spent in planning and understanding the context within which each partner is working during partnership inception is critical. It facilitates the development of realistic objectives and projects that align to the context of the organizations involved.

Timely and appropriate resource allocation is key to implementation of the partnership objectives. However, few 
partnerships have the ability to monitor the costs of their activities systematically while others have difficulties comparing the costs to their achievements [2]. This challenge affects resource and timeframe allocation in many partnership projects.

Most partnership funding is geared towards meeting short term objectives and hence projects tend to address more of the symptoms and not the root causes of the identified gap.

Prolonged delays in contract approval and erratic funding cycle causes frustrations among participating organizations. Yet at the same time these organizations are pressurized to undertake projects within schedule and ensure timely reporting. This expectation reflects an inadequate understanding of organizational processes and is often linked to dominance and financial control of donors and other stakeholders.

There is need for provision of resources at two distinct levels for partnerships to succeed. The first is at the partnership level; organizations and donors need to ensure that enough funds are available to maintain and sustain the partnership as an entity.

Funders often promote the concept of collaboration but rarely do they provide adequate resources for the time-consuming nuts and bolts work of partnership building [37].

Partnerships and other forms of collaboration are evolving relational arrangements that become ineffective depending on how they are initiated, developed, managed and allocation of resources to strengthen the partnership itself is key. [38].

The second level is organizational. Funding is required to manage organizational processes that support project operations and staffing. Organizations involved in partnerships especially those with a small number of staff, were observed to have been stretched thin by the collaborative process [37].

Multi-year funding and planning is one approach considered to be effective because it protects organizations from leadership changes at the partnership level and it enables NGOs engage in long range planning of relevant and sustainable project interventions. It enhances the resilience of the organization and promotes more focused programming.

Partnerships also have the capacity and flexibility to provide scalable and appropriate funding to its members as the partnership objectives and external environment change [7].

Adopting proactive approaches ensures that a partnership's benefits and outcomes consistently extend beyond the immediate stakeholders involved and the duration of the engagement.

\section{Discussion and Conclusion}

Partnerships are formed for diverse reasons, and each has a "life" of its own. Even when everything functions well, it does so within a given context: whenever changes occur and new objectives or strategies are introduced then the conditions required for the partnership to succeed change.

The observation from the study was that NGO partnerships are important in bringing diverse organizations to work together across a number of focused areas. However there is need for more empowering partnership processes.

The success of any partnership depends on diverse success factors being present during each phase of the partnership lifecycle. Unfortunately, unhealthy behaviors in a partnership tend to stifle the ability of individuals or organizations to find and create new value [39]. The five aspects highlighted by the study require a collaborative atmosphere to promote their existence and growth.

Successful partnerships rely upon the use of both "hard" technical skills and "soft" skills, which include interpersonal and relationship-building abilities [27]. Four out of the five areas prioritized by the respondents require the use of "soft" skills or relational skills for them to develop.

Unfortunately, more attention is currently devoted to monitoring the effectiveness of programmatic and funding aspects of the partnership while the relational or 'intangible' drivers for partnership success are overlooked or their impact underestimated.

For example, partnership principles are often ignored or easily overlooked and this results to partners taking each other for granted and relegating to second place relationship management over the partnership's project (s) or their individual organizational priorities [40].

Yet, partnerships will not thrive where there is a narrow focus on only the programmatic and funding success factors. Partnerships are open systems and their growth also relies on "soft or intangible aspects. The soft side refers to the development and management of relationship capital in the alliance. It is through relationship capital that the partnership is actually developed and implemented [26].

For example, trust was identified as an important aspect in developing and maintaining organizational relationships [28]. Trust is enhanced when each organization is committed to the partnership vision and purpose. Commitment, communication, shared vision and purpose are aspects that enable different partnering entities to look beyond their perceived expectations or interests and focus on the partnership progress.

It has also been observed that without strong leadership and a high level of trust, project momentum often slowed down [41].These examples emphasize the need to consistently focus on the 'soft' or relational aspects that drive partnerships success. Ideally, as a partnership progresses different practices and attitudes are required at both partnership and organizational level if the partnership is to continue to sustain its outcomes, success and value.

Strategic partnerships may take years to fully mature, signs of success are progressive and require time to develop [42]. Therefore, there is a need for partnerships to develop indicators of success that go beyond programmatic and financial aspects to aspects that facilitate positive relationships among the partners.

Partnerships to some extent are not alike and yet it is possible to ensure their success by considering the already documented enabling factors during initiation and then consistently monitoring the factors as the partnership progresses.

Developing clear benchmarks during inception and monitoring the advancement of the key drivers of success during each partnership phase is key. Secondly this will assist in the identification of potential risks or promising practices 
throughout the partnership lifecycle.

Undertaking periodic partnership health checks is one way of ensuring that the project objectives, partner relations, contractual obligations and governance structures promote the key drivers of success. This will guarantee that organizations and individual's passion for the partnership success are kept alive.

\section{References}

[1] Graas Susan, Annette Bos, Caroline Figuères (UNESCO-IHE) \& Tunde Adegoke, (2007). Partnerships Water and Sanitation. Thematic Overview paper. IRC International Water and Sanitation

Centrehttp://www.pacificwater.org/userfiles/file/IWRM/Toolb oxes/TOP18_PartnerSHIPS_07.pdf

[2] Audit Commission (2005) Governing partnership: Bridging the accountability http://informationsharing co.uk/wp-content/uploads/2012/08 Audit-commission-governing-partnerships.pdf

[3] Hoksbergen, Roland. (2005). Building Civil Society through Partnership: Lessons from a Case Study of the Christian Reformed World Relief Committee. Development in Practice 15(1):

16-27.

http://policy-practice.oxfam.org.uk/publications/building-civil -socity-through-partnership-lessons-from-a-case-study-of-thechr-130696

[4] Hoxtell Wade, Maximilian Norz, Julia Steets and Kristina Thomsen (2013) UN-Business partnerships: A handbook. New York: United Nations Global Compact Office. https://www.unglobalcompact.org/docs/issues_doc/un_busines s_partnerships/UNBusinessPartnershipHandbook.pdf $\{$ Accessed on 15.2.2015)

[5] Fowler, Alan. (2000) Partnership: Negotiating Relationships A Resource for Non-Governmental Organisations, Occasional Paper Series No. 32, Oxford: INTRAC. \{Accessed 15th June 2018)

http://cercle.lu/download/partenariats/INTRACPartnershipneg ociatingrelationship.pdf

[6] Austin and Seitanidi (2012).Collaborative Value creation: A Review of Partnering Between Nonprofits and Businesses

[7] https://study.sagepub.com/sites/default/files/austinseitanidi.pdf

[8] Maselli Daniel, Jon-Andri Lys, Jacqueline Schmid (2006) Improving Impacts of Research Partnerships. Swiss Commission for Research Partnerships with Developing Countries, KFPE http://passthrough.fw-notify.net/download/309471/http://www .kfpe.ch/download/KFPE_ImpactStudy-final.pdf

[9] Shannon Kindornay, Stephanie Tissot, and Nabeel Sheiban (2014) The Value of Cross-Sector Development Partnerships. North-South institute. Accessed May 15th 2018. www.nsi-ins.ca

[10] Spekman Robert, Issabella Lynn and MacAvoy Thomas, (2000) Alliance competence: Maximizing the value of your partnerships. New York. John Wiley \&Sons Inc.

[11] Steve Rochlin, Simon Zedeck and Mara, (2008), Governing Collaboration; Making Partnerships Accountable for Delivering Development \{Online Accessed on 24 June 2018\} upan1.un.org/intradoc/groups/public/documents/.../unpan0319 87.pdf
[12] Lasker, R. D., Weiss, E. S. and Miller, R. (2001) Partnership Synergy: A Practical Framework for Studying and Strengthening the Collaborative Advantage. The Milbank Quarterly 79(2), 179-205.

[13] Jones Jacky and Margaret M. Barry (2011), Exploring the relationship between synergy and partnership functioning factors in health promotion partnerships Health Promot. Int. (2011) 26 (4): 408-420. \{Accessed on 15. 7. 2018\} http:/heapro.oxfordjournals.org/content/26/4/408.full

[14] Xavier De Souza Briggs (2003) Perfect Fit or Shotgun Marriage? Understanding the Power and Pitfalls in Partnerships

http://web.mit.edu/cpsproject/images/PerfectFit.pdf \{accessed on 5.7.2018\}

[15] Fowler, A. \& McMahon, J. (2010),Self-Assessment of a Multi-Stakeholder Collaborative Process. Findings and Lessons from a Survey of a Consortium for the Enhanced Livelihoods in the Mandera Triangle (ELMT) and Enhanced Livelihoods in Southern Ethiopia (ELSE) Program 2007-2009. Consortium Survey Report.

[16] Zahner, S. J. (2005), Local Public Health System Partnerships. Public Health- Reports, 120, 76-82. https://www.ncbi.nlm.nih.gov/pmc/articles/PMC1497678/pdf/ 15736335.pdf.

[17] International Finance Corporation, (2007) Stakeholder engagement Washington. International Finance corporation \{Online Accessed on 3rd July 2018\}.

[18] Kale Prashant and Harbir Singh (2009) Managing Strategic Alliances: What Do We Know Now, and Where Do We Go From Here? Volume 23(3); The Academy of Management Perspectives. http://amp. aom.org/content/23/3/45.full

[19] Batti Rehema C, (2015) Community based partnerships: Nurturing Strategic NGO collaboration. North Charleston, SC: Create Space.

[20] Mohr, Jakki. and Spekman, Robert. (1994), Characteristics of partnership success: Partnership attributes, communication behavior, and conflict resolution techniques. Strat. Mgmt. J., 15: 135-152. doi:10.1002/smj.4250150205

https://www.jstor.org/stable/2486868?seq=1\#page_scan_tab_c ontents

[21] Glasby Jon \& Edward Peck (2006) We have to stop meeting like this: The governance of inter-agency partnerships. ICN governance of Interagency partnerships .A discussion paper

[22] http://www.wales.nhs.uk/sitesplus/documents/829/ICN\%20Go vernance $\% 20$ of $\% 20$ Inter-Agency $\% 20$ Partnerships $\% 202006$.p df \{accessed 19.5.18\}

[23] CCF National Resource Center and Mark Publow (2010) Partnerships: Framework for Working Together. Accessed on 15. 8. 2018\}

http://strengtheningnonprofits.org/resources/guidebooks/Partn erships.pdf

[24] Pope J and Jolly P (2008), Working in partnership: practical Advice for running effective partnerships, Department of planning and Community development, Melbourne Australia \{Accessed on 4. 8.2018\} http://www.vcoss.org.au/documents/VCOSS\%20docs/HSPIC/ 00911_vcoss_partner_guide_1_WEB.pdf

[25] Shah, R., \& Swaminathan, V. (2008). Factors influencing partner selection in strategic alliances: The moderating role of alliance context. Strategic Management Journal, 29(5), 471494. 
[26] Tennyson Ros (2004), Partnering tool-book. An essential guide to cross-sector partnerships $\mathrm{http}$ //thepartneringinitiative.org/tpi-tools/toolbook-series/thepartnering-toolbook/

[27] Zaman Manir and Felix Mavondo, (2008), Measuring alliance success. The Role of Strategic fit.

http://docplayer.net/38135454-Measuring-alliance-success-the -role-of-strategic-fit-manir-zaman-felix-mavondo-monash-uni versity-abstract.html

[28] Cullen John, Jean L. Johnson, Tomoaki Sakano (2000), Success Through Commitment and Trust: The Soft Side of Strategic Alliance Management. https://www.researchgate.net/profile/John_Cullen6/publicatio n/223432934_Success_Through_Commitment_and_Trust_Th e_Soft_Side_of_Strategic_Alliance_Management

[29] Squire Catherine, (2012) Partnerships and capacity building; A guide for small and diaspora NGOs. \{Accessed 9.7. 2018 \} http://www.publichealth.ie/files/file/IPHliterature.pdf

[30] Kjaer Louise, Peter Abrahamson \& Peter Raynard (2003) Local partnerships in Europe - An action research project. The Copenhagen, Copenhagen Centre

[31] http://citeseerx.ist.psu.edu/viewdoc/download?doi=10.1.1.130 $.5298 \&$ rep $=$ rep $1 \&$ type $=$ pdf

[32] Kohm, A., La Piana, D. \& Gowdy, H. (2000) Strategic Restructuring: A Study of Integrations and Alliances among Nonprofit Social Service and Cultural Organizations in the United States, Chapin Hall Centre for Children, University of Chicago. [Online, accessed 19 July 2018] URL: http://www.chapi.nhall.org/article_abstract.

[33] Edgar, Marshall \& Bassett (2006: 9) Partnerships: Putting Good Governance Principles In Practice. Institute of Governance https://www.files.ethz.ch/isn/99462/2006_partnerships.pdf

[34] Brandstetter, et al, (2006) Successful partnerships: A guide. OECD LEED forum http://www.fonduri-ue.ro/posdru/images/downdocs/brosura $p$ arteneriate_de_succes.pdf

[35] Hilary Binder-Aviles, (2012) NGO handbook. \{Accessed on 15th February 2015\} http://photos.state.gov/libraries/amgov/30145/publicationsengl ish/B_20121023_NGO\%20Handbook_English_150.pdf
[36] Laura, Claire, \& Michael (2006) Partnerships: Putting Good Governance Principles into Practice. Institute on Governancehttps://iog.ca/docs/2006_August_partnerships.pdf

[37] Stott, Leda (2005), Partnership Matters. Current issues in cross sector collaborations. Issue 3; Partnering Initiative. Cambridge University Press. Cambridge

[38] Boydell, Leslie, (2007) Partnerships: A literature review. Dublin: Institute of Public Health in Ireland. http://www.publichealth.ie/files/file/IP Hliterature.pdf

[39] Brehm, Vicky Mancuso (2001) Promoting effective North South NGO Partnerships: A comparative Study of 10 European NGOs', INTRAC: The International NGO Training and Research Centre Occasional Papers Series, Number 35. $\begin{array}{llll}\text { Accessed } & 18 . & 2015\end{array}$ http://dspace.africaportal.org/jspui/bitstream/123456789/2178 4/1/Promoting\%20Effective\%20North\%20South\%20NGO $\% 2$ OPartnerships.pdf

[40] Smock Kristina (1999) Building effective partnership: The process and structure of collaboration. Issue \# 105,May/June 1999 http://www.nhi.org/online/issues/105/smock.html-accessed 18.2.2015

[41] Fowler, A. and McMahon, J, (2010) Self-Assessment of a Multi-Stakeholder Collaborative Process. Findings and Lessons from a Survey of a Consortium for the Enhanced Livelihoods in the Mandera Triangle (ELMT) and Enhanced Livelihoods in Southern Ethiopia (ELSE) Program 2007-2009. Consortium Survey Report

[42] Kittel Joe, (2012) Spiritual principles in strategic alliances. USA.(e-book )

[43] Halper Eva, (2009) Moving on. Effective management for partnership transitions, transformations and exits. The Russell Press.

[44] Graham Allen, Catherine Evans and Catherine State, (2015), Building better collaboration; University of Birmingham. http://www.birmingham.ac.uk/Documents/college-social-sciec es/govement-society/inlogov/research/2015/building-better-co llaboration.pdf

[45] Bardin Luc, Raphael \& Guillaume (2014) Strategic Partnering: Removing chance and deliver consistent success. Great Britain. Kogan Page Limited. 